\title{
Şirket Karlılığı İle Şirketin Vizyon İfadesi Arasındaki İlişkiye Stratejik Yönden Bir Bakış: BİST Şirketleri Üzerine Bir İnceleme
}

DOI: $10.26466 /$ opus.583801

*

\section{$\underline{\text { Safa Acar* }}$}

\begin{abstract}
*Öğr. Gör., Siirt Üniversitesi, Kurtalan Meslek Yüksekokulu, Kurtalan/Siirt/Türkiye
\end{abstract} E-Posta: safaacar@siirt.edu.tr

ORCID:0000-0002-9578-0198

Öz

İşletmeler varlkklarına bir sebepten başlarlar. Bu sebep işletmenin amaç ve hedeflerini oluşturmasına yardımo olur. Oluşan amaç ve hedefler var oluş sebebi ile birlikte işletmenin vizyonunu oluşturur. İşletmelerin vizyon ifadeleri, bu üç değer olan misyon, amaç ve hedeflerin bir bileşkesi yapısındadır ve işletmenin gelecekte hangi noktada olmak istediğini ve geleceğe yönelik olarak planladıklarını gösteren bir yapıdadır. İşletmeler vizyon ifadesi ile kendi gelişimlerine katkıda bulunurlar. Vizyon ifadesi işletmelerin uzun ömürlü olma, karlı bir şirket olma ve başarılı adımlar atma gibi beklentilerini karşılayabilecek bir yapı oluşturur. Çalışmanın amacı da bu hedeflerden biri olan işletme karlılığı ile vizyon ifadesinin arasındaki ilişkiyi ortaya koymak şeklinde belirtilebilir. Borsa İstanbul'da işlem yapan ve son 20 yıldır artarda kar açılayan işletmelerin vizyon ifadeleri incelenmiş ve Akgemci ve Güleş'in (2009) ortaya koyduğu vizyon ifadesinde olması gereken kriterler çerçevesinde analiz edilmiştir. Elde edilen bulgular sonucunda vizyon ifadelerinde bu değerleri barındıran şirketlerin karlılıklarının sürekli olabileceği sonucuna ulaşılabilir.

Anahtar Kelimeler: Stratejik Yönetim, Vizyon Ifadesi, Borsa İstanbul, Karlllk 


\title{
Strategic Perspective on The Relationship Between Company Profitability and The Vision of The Company: A Review on BIST Companies
}

\begin{abstract}
Businesses start their assets for a reason. This causes the business to create goals and objectives. The goals and objectives that are formed constitute the vision of the company together with the reason of existence. The vision statements of the enterprises are in the form of a combination of these three values, the mission, the goals and the objectives, and it is in a structure that shows what the business wants to be in the future and what they plan for the future. Businesses contribute to their development with vision. Vision is a structure that can meet the expectations of enterprises such as long life, being a profitable company and successful steps. The aim of the study is to reveal the relationship between one of these objectives, business profitability and vision. The vision statements of the enterprises that traded on Borsa Istanbul and announced profits for the last 20 years were analyzed in the framework of the vision statement of Akgemci and Güleş (2009). As a result of the findings obtained, it can be concluded that the profitability of the companies containing these values may be continuous in the vision statements.
\end{abstract}

Keywords: Strategic Management, Vision Statement, Borsa İstanbul, Profitability 


\section{Giriş}

Daha önceki dönemlere göre daha zor şartlarda hayatlarını devam ettirmek zorunda kalan işletmelerin kendilerini rakiplerinden daha rekabetli bir konuma taşıyabilmeleri için yeni bir takım çözümler geliştirmeleri gerekmektedir. Bu çözümler, temelde işletmenin rekabet avantajı kazanmasına da katkılar sağlamalıdır.

Stratejik yönetim, işletmelerin geleceğe güvenle bakmalarına katkı sağlayacak bir takım faydalar sağlayan bir yönetim tarzıdır. Bu sebeple uzun ömürlü olmak, karlılık oranlarının yüksek olmasını beklemek ve performans seviyesinin yükselmesini istemek gibi hedefleri olan işletmeler bu çalışmalara yoğunlaşmaktadır. Son dönemlerde giderek artan rekabetçi piyasa yapısı işletmelerin rakiplerinden daha önde olmalarını zorunlu kılmaktadır. Bu sebeple işletmeler, rakibinden bir adım önde hareket etmeli ve işletmelerini stratejik yönetim uygulamalarına uyumlu hale getirmelidir.

Yoğun rekabet ortamında çalışmak zorunda kalan işletmeler, uzun ömürlü bir hayat sürebilmek, sürdürülebilir bir rekabet avantajı elde etmek ve sektör ortalamasının üzerinde bir kar beklentisi ile çeşitli yöntemler uygulamaktadırlar. Bu uygulamaların son dönemde en ilgi çekici olanlarından biri de yine stratejik yönetim uygulamaları ve bu kapsamda değerlendirilen unsurlardır. Stratejik yönetim sayesinde uzun ömürlü karlı ve rekabet avantajı elde eden işletme hayali gerçek olabilmektedir. Bu kapsamda işletmeler ömürlerinin başlarından itibaren her alanda gelişmeler göstererek bu yönde çalışmalara yönelmektedirler.

Stratejik yönetim kapsamında misyon ifadesi, vizyon ifadesi, değerler ve amaçlar tam olarak belirlenmesi gereken unsurlar olarak kabul edilebilir. Misyon ifadesi, işletmeye amaç kazandırırken, vizyon ifadesi yön verir. Değerler ise günlük çalışma durumuna bağlı olarak gerçekleşir (George, 1997, s.66). İşletmelerin geleceğe yönelik olarak oluşturdukları, uzun ömürlü olma ve karlılık gibi hedefleri sağlamak adına yaptıkları çalışmalar stratejik yönetim kapsamında uygulanabilmektedir. Stratejik yönetim kapsamında değerlendirilen bu unsurlardan geleceğe yönelik olan ifadeler barındıran unsuru, vizyon ifadesidir. Vizyon ifadesinin işletme performansına olan etkisi ve katkısı ile ilgili literatürde birçok çalışma mevcuttur (Akgemci, Çelik, ve Ertuğrul, 2004; Doğan ve Hatipoğlu, 2009; 
Özer, 2010; Karaman, 2005). Yapılan bu çalışmalarda işletmelerin vizyon ifadeleri ile performansları arasındaki bağlar mercek altına alınmıştır.

Bu çalışmanın temel amacını, karlılık ile vizyon ifadesi arasındaki ilişkinin stratejik yönünü belirlemek oluşturmaktadır. Bu kapsamda, Borsa İstanbul'da işlem gören ve son 20 yıldır kar açıklayan işletmelerin, kendi yapılarına özgü olarak oluşturdukları ve paydaşları ile paylaştıkları vizyon ifadeleri ile işletme karlılığının ve işletme başarısının arasında oluşan bağlar belirlenmek istenmektedir. İşletmelerin vizyon ifadeleri, daha önce literatürde belirlenmiş olan, başarılı bir vizyonda olması gereken unsurlardan kaçını bünyesinde barındırdığına göre kategorileştirilerek genel bir analize tabi tutulmuştur.

Çalışmada, öncelikle vizyon ifadesi ile ilgili genel bilgilere yer verilmiş ve bu kapsamda bir literatür çerçevesi oluşturulmuştur. Daha sonra araştırma sonucunda elde edilen veriler siralanarak elde edilen bulgular kapsamında bazı sonuçlara ulaşılmıştır. En son bölümde ise elde edilen bulgular ile literatür karşılaştırmalı olarak incelenmiş ve sonuç ve öneriler kısmı sunulmuştur.

\section{Kavramsal Çerçeve}

\section{İşletmenin Vizyonu}

Vizyon ifadesi, stratejik yönetim uygulamalarına yönelik çalışmalar yapan işletmelerde olması gereken ve rekabetçi olabilmek adına büyük bir gereklilik durumunda olan bir unsurdur. İyi bir vizyon ifadesi işletmeyi takip eden paydaşlara iyi bir ilham vermelidir (Kirkpatrick, 2008, s.5). Vizyon ifadesi işletmenin ideolojik temellerini ve geleceğe yönelik sahip olduğu hayalleri barındırmaktadır. İdeolojik temelleri, işletmenin varlık sebebine, özgün kimliğine ve ısrarla sahip olduğu özelliklere odaklanırken, gelecek ile ilgili oluşturduğu hayaller ise işletmenin 10 ile 30 yıl arasında olmak istediği yere odaklanır. Bu sebeple işletmenin o andaki imkânlarını aşan ihtiyaçlar barındırmaktadır. Oluşturulan vizyon ifadesi işletmeyi hem teşvik etmeli hem de zorlayıcı olmalıdır (Tanković, 2013, s.332). Vizyon ifadesi ile işletmenin gelecekte yapacağ 1 faaliyetlerin işletme yöneticisi tarafından ifade edilmesi, vizyon ifadesinin başarılı olmasını sağlamaktadır (Erden, Ayhün, Çavuşgil ve Köse, 2018, s. 532). Bu çerçevede 
başarılı olan işletmeler, yaptıkları uygulamaları çevresel koşullara göre ve işletmenin içine göre adapte ederken aynı zamanda belirli bir vizyon, amaç ve hedefe sahip olmaktadır. Başarılı olan kurumlar, işletmeler ve toplumlar incelendiği zaman bütün bu yapıların birer vizyon ifadesine sahip olduğu görülmektedir (Ülgen ve Mirze, 2013, s.177).

İşletme literatürüne bakıldığında vizyon ifadesi ile ilgili bir çok tanımin olduğu ve bu tanımların her birinin farklı noktalara temas ettiği görülmektedir. Bu çalışmada farklı noktalara odaklanan tanımların ardından ortak bir tanım oluşturulmaya çalışılmıştır. Genel olarak vizyon ifadesi, işletmenin kendi isteği ile belirlediği ve gelecekte kendisini görmek istediği noktanın bir ifadesi olarak tanımlanabilir. Bu çerçevede vizyon ifadesi bütün çalışanları kapsamaktan ziyade sadece yöneticilerin zihinlerinde oluşan işletme hakkındaki hayalleri ve hedeflerin tamamıdır (İnce, 2015, s.146).

Vizyon ifadesi, işletmenin varlık nedenini, yaşama gayesini ve bunun gibi temel değerlerin oluşturduğu kabullenmelerin çizmiş olduğu bir ufuktur. Bu ufuk işletmenin geleceğe bakışını, sahip olduğu değerler çerçevesinde değerlendirerek bir sonuç meydana getirir (Bircan, 2002, s.16). Lamba'ya (2014) göre vizyon ifadesi, “kuruluşun ne olduğunu tanımlar; kuruluşun var oluş nedeni ifade eder; kimliğinin odağında yer alır; kuruluşun, kaynaklarını, yeteneklerinin, kapasitesinin, nereden gelip nereye gittiğinin ve varlık sebebinin ifadesidir" olarak tanımlanmaktadır (Lamba, 2014, s.85). Vizyon ifadesi, bir öngörü, geleceğin tasarlanmış bir görüntüsü, geleceğe yönelik bir resim ya da bir ideoloji olarak kabul edilebilir. Bu çerçevede sınırları çizilemeyen bir hayal gücü olarak düşünülebilir. Örgüt için vizyon ifadesi bir hayalden öte genel ve soyut bir hale dönüşmüş yön belirtir. Vizyon ifadesi oluşturan bir işletme geleceğe bir köprü kurmuşlardır (Duman, 2007, s. 5,6). Vizyon ifadesi, içerisine amaç ve değerleri de dahil eden bir felsefe ve bir somut görüntüler bütünüdür (Collins ve Porras, 1991, s.31).

Çoğu zaman bir vizyon ifadesi ani ve devrimci bir biçimde oluşur. Oluşum döneminde hangi değerlerin korunup hangi değerlerin değiştirileceği veya tamamen terk edileceği, önceliği olan konuların hangileri olduğu, hangi konuların görece olarak daha önemsiz olduğu gibi sonuçlara ulaşabilmek için "ne için" sorusuna gerçekçi bir yanıt aramak vizyon ifadesinin anlamını ortaya çıartır (Papatya, 1998, s.125). 
Bir işletmenin vizyon ifadesi, amaçlarının değerlerinin ve hedeflerinin en temel göstergesidir. İşletme ile ilgili olanların duyguları ve düşüncelerine, işletmenin bir sesleniş biçimidir. Bu çerçevede değerler, amaçlar ve hedefler bir vizyonun temel bileşenleridir. İşletmeler vizyondan gereken faydayı görmek için vizyonlarını bir slogan biçiminde ifade etmelidirler. Her işletmenin içinde bulunduğu toplumsal değerler vizyon üzerinde etkili olduğundan dolayı her toplumda farklı vizyon ifadelerine rastlamak mümkün olmaktadır (Soygür, 2018, s.989).

Bir işletmenin vizyon ifadesinin en önemli özelliği, ulaşılamaz bir konumda olmasıdır. Ulaşılamaz olmasının sebebi, işletmelerin kurulurken sonsuz bir ömür biçilerek kurulmuş olmalarındandır. Eğer bir işletme hedeflediği vizyonuna ulaşırsa hemen yeni bir vizyon belirlemeli ve gelişmenin önünü açmalıdır (Melek, 2012, s.74).

Ülgen ve Mirze'ye (2013) göre vizyon ifadesi, "gelecekteki varılması veya olması arzu edilen bir durumla ilgili rüya veya hayalin ifade edilmiş bir şeklidir." Olarak ifade edilmektedir. Diğer bir değişle bir vizyon ifadesi bir işletmenin ya da bir bireyin gelecekte olmak istediği durumun bir fotoğrafı veya bir resmi olarak nitelendirilmektedir. Vizyon ifadesi stratejik yönetim içerisinde çok önemli bir başlangıç noktasıdır. Vizyon ifadesi sayesinde işletmeler amaç ve hedeflerini oluşturabilmektedirler (Ülgen ve Mirze, 2013, s.177).

Buraya kadar yapılan tanımların ortak noktalarına bakıldığında vizyon ifadesinin, geleceğe ulaşmak için hazırlanan bir köprü, bir umut, bir hedef, bir hayal ve bir yön olduğu açıkça görülmektedir. Bu kapsamda işletmelerin vizyon ifadelerini net bir biçimde belirlemeleri aslında işletmenin hangi yöne gideceğini, hangi hayallere sahip olduğunu ve gelecekte kendisini nerede görmek istediğini ortaya koyan bir ifade beyanı olarak kabul edilebilir.

\section{İşletmelerde Vizyon Ífadesinin Önemi}

İşletmeler vizyon ifadesi ile kendilerine bir yön belirlemekte ve bu sayede belirledikleri değerler ve amaçlarına ulaşabilmektedirler. Vizyon işletmelere içinde bulundukları rekabetçi piyasalarda başarılı olabilmenin yollarını sunmakta yara sağlayabilmektedir. Vizyon ifadesi işletmelerin bir 
resmi olduğu için, paydaşlarına hangi sebepten dolayı bu geleceği oluşturmak zorunda olunduğunu ifade eden en önemli değerdir. Vizyon ifadesi sayesinde çalışanlar, müşteriler ve diğer ilgililer işletme hakkında bilgiye sahip olurlar ve vizyon ifadesi sayesinde işletmenin hangi yöne gitmek istediğini tayin edebilirler. Bu sayede işletme ile ortak bir hedef belirleyerek yüksek düzeyde motive olabilirler (Özer, 2010, s.7).

Vizyon ifadesi, çalışanlara işletmenin geleceği konusunda bir rehber görevi görür. İşletmenin yatırımcılarına da gelecekte belirlenmiş olan hedeflere ulaşmada hangi adımları atmaları gerektiği ile ilgili yol gösterici ilkeler sunar. Vizyon ifadesi sayesinde işletmenin çalışanları işletmenin hedeflerine yönlendirilir ve çalışanların verimsiz işler yapmasının önüne geçer. Vizyon ifadesi olmayan bir işletme rotası olmadan denizde ilerlemeye çalışan bir gemiden farksızdır. İşletmede vizyon ifadesi olduğu zaman işletme, işbirliğine, yenilikçiliğe ve rasyonel davranışa doğru yol alır. Ancak vizyon ifadesi olmayan bir işletme, başarısızlığa, yeteneksizliğe ve kaosa doğru yol alır (Ülgen ve Mirze, 2013, s.178).

Vizyon ifadesi işletmenin stratejik yönetim uygulamaları için de büyük öneme sahip bir konumdadır. Vizyon sayesinde işletme içerisinde ortak hedefler ve ortak inançlar oluşturulabilmektedir. İşletmenin hangi yöne gittiğini belirleyen en önemli etken olan vizyon ifadesi, işletme ve bireyler arasında ortak bir imajın oluşmasına da katkı sağlamaktadır (Doğan \& Hatipoğlu, 2009, s.83).

Vizyon gelecek ile ilgili bir yönetim aracıdır. Örgütlerin sahip oldukları kurum kültürünü, gelecek ile ilgili oluşturdukları perspektifi, yöneticilerin çevrelerine yönelik algılarını ve dünya görüşlerini belirleyen en önemli paradigma olarak kabul edilebilir. Bu sayede işletmenin amaç ve hedeflerini ve bu amaç ve hedeflere giderken hangi yolları izlemek gerektiğini ifade etmesi yönünden işletme için önemli bir kavram olmaktadır (Çetin, 2009, s.97).

\section{Vizyon İfadesinin Özellikleri}

Vizyon ifadesi işletme içi çok önemli ve değerlidir. Bu sebeple oluşturulurken bazı özellikleri barındırması kaçınılmaz olarak gereklidir. Ülgen ve Mirze (2013) Vizyon ifadesi oluşturulurken iki temel yolun izlenmesi ge- 
rektiğini ifade etmektedirler. Bu yollardan birincisi, vizyon ifadesinin kurucu yada lider tarafından daha önceden belirlenerek işletmenin üyeleri ile paylaşılması ve geliştirilmesi yöntemidir. İkinci yöntem ise vizyon ifadesinin yöneticiler ve çalışanların beraber oluşturmasıdır. Birinci yöntemde önemli olan yöneticilerin liderlik yeteneğinin gücü ile doğru orantılı olarak başarı elde edilebilirken ikinci yöntemde yönetim ve çalışanlar arasındaki iletişim büyük önem kazanmaktadır (Ülgen ve Mirze, 2013, s.181).

Yalçın (2002) kaliteli ve işletme için faydalı olabilecek bir vizyon ifadesinin bazı özellikleri barındırması gerektiğini ifade etmektedir. Bu özellikler (Yalçın, 2002, s.61; Çetin, 2009, s.97);

- “Geleceğin neye benzediğini göstermelidir (hayal edilebilir olmak).

- Çalışanlar, müşteriler ve hissedarlar için uzun vadede cezp edici olmalıdır (cazip olmak).

- Gerçekçi amaçlara sahip olmalıdır (ulaşılabilir olmak).

- Karar vermede yeteri kadar açık yön göstermelidir (odaklanmış olmak).

- Değişen koşullara göre kişilere inisiyatif imkanı vermelidir (esnek olmak).

- Diğer insanlara kolaylıkla anlatılabilir olmalıdır (iletilebilir olmak)."

Vizyon ifadesi, gerçekçi olmalı, uygulanabilir bir yapıda olmalı, bütün işletme sistemlerini harekete geçirebilmeli, çalışan bireylere esin kaynağ 1 olarak amaçlara da ayna olmalı, örgütsel bağlılık sağlamalı, işletmeyi geleceğe yöneltmeli, olabilecek en optimum süre içerisinde oluşturulabilmeli, bireylerin dikkatlerini odak noktaya yoğunlaştırabilmeli, işletmenin amaçlarını ve stratejilerini dönüştürebilmeli, yön anlayışı verebilmeli, üst yönetim tarafından desteklenmeli ve bireylere bir vizyon katmalıdır (Akgemci, Çelik ve Ertuğrul, 2004, s.4).

Eren (2002) vizyon ifadesinin özelliklerini şu şekilde belirtmiştir (Çetin, 2009, s.97):

- "Her yönetici ve lider için orijinaldir.

- Tüm faaliyetlerin algılanmasını gerektirir.

- Paylaşıldıkça değer kazanır.

- Stratejilere yön verir. 
- Stratejistlerin yaratıcılık, yenilikçilik, risk alma, katılımcılık nitelikleri hakkında bilgi verir."

- Bir işletmenin etkin vizyon oluşturabilmesi için gereken Tom Peters'in sekiz ilkesi ise şu şekildedir (Aktan, 2019; Doğan ve Hatipoğlu, 2009, s.85);

- Etkin vizyon işletmenin içindeki bireylerin oluşturduğu hareketleri üzerinde etki oluşturacak düzeyde olmalı,

- Açık bir yapıda olmalı ve işletmenin başarısını kamçılamalı,

- Mükemmeli aramalı,

- Katı kurallara değil esnek kurallara sahip olmalı,

- İstikrarlı ve sürekli yeniliklere açık olmalı,

- İşletme çalışanlarına yetki devri yapılmasını amaçlamalı,

- Geçmişi şerefle anmalı ve geleceğe yönelik hazırlıkları olmalı,

- Ana hedefi Mükemmeliyeti sağlamak olmalıdır.

İşletmenin oluşturduğu vizyon bildirisinin çalışanlar ile paylaşılması aşamasında da bazı noktalara önem verilmesi gerekmektedir (Ülgen ve Mirze, 2013, s.181). Bu noktalar şu şeklide sıralanabilir:

- Vizyon ifadelerinin ve amaçların açık bir şekilde belirlenmesi gerekir.

- Vizyonun temel aldığı gerçekler sürekli olarak ve açık olarak vurgulanmalidir.

- Vizyonda üzerinde durulan noktanın çalışanları "biz" kavramında birleştirmesi ve işletmeden gurur duymalarını sağlamak olmalıdır.

- Vizyon ifadesi hazırlanırken işletmedeki çalışanların görüşleri de alınarak onlara danışılmalıdır. Bu yapılırken eşitlik ilkesine sadık kalınmalıdır.

- Bütün bunlar oluşturulurken temel amaç, vizyon ifadesi oluşturmanın ötesinde gerçek bir vizyon oluşturmak olduğu unutulmamalıdir.

\section{Vizyon Ifadesinde Yer Alan Unsurlar}

Bir işletmenin vizyon ifadesini tek başına oluşturması o işletmenin gelecekte ulaşmak istediği noktaya ulaşabilmesi adına yeterli bir hamle değildir. Vizyon ifadesinin oluşturulması aşamasında işletmede çalışanların 
misyon, işletme amaçları, işletme hedefleri ve işletmeye ait olan değerlerin hepsini özümsemesi gerekmektedir (Ülgen ve Mirze, 2013, s.181). Bu çerçevede işletmenin vizyon ifadesi Şekil 1'de gösterildiği gibi ifade edilebilir.

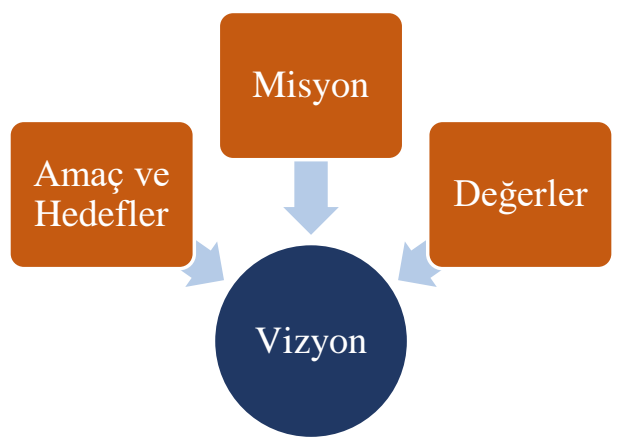

Şekil 1: Vizyon İadesinin Unsurlar

Şekil 1'de ifade edildiği gibi bir vizyon ifadesinin unsurları arasında misyon ifadesi, amaç ve hedefler ve değerler yer almaktadır. Bu ifadelerin ne oldukları kısaca tanımlanırsa;

Misyon ifadesi, bir işletmenin var oluş nedenini ve örgütün hangi hedefleri başarabilmek için var olduğunu belirten bir ifadedir. Hazırlanan misyon ifadesi örgütün ya da işletme bölümünün veya biriminin neyi gerçekleştirme amaciyla var olduğunu ve bu bölüm yada birimin sorumluluklarının ne olduğunu belirtmelidir (Muslu, 2014, s.154).

Amaç, işletmenin neyi elde etmek istediğini ifade eden bir kavramdır. Amacın işlerlik kazanabilmesi için işletmenin geleceğe yönelik olarak belirlediği hedefleri doğrultusunda bir yön oluşturması ve işletmenin sahip olduğu ortak değerleri taşıyan bir yapıda olması gerekir (Ülgen ve Mirze, 2013, s.181).

Hedefler, amaçların nicelik olarak belirlenmiş durumları olarak kabul edilebilir. İşletme faaliyetlerinin sonucunda elde edilmek istenen kavramlar amaçları oluştururken bu kavramların somutlaştırılması sonucu hedefler ortaya çıacaktır (Ülgen ve Mirze, 2013, s.182).

Değerler ise bir örgütün belirlenen sınırları içerisinde üyelerinin güvenli olarak hayatlarını sürdürmelerini ve gelişmelerini sağlamak ama- 
cıyla birbirleri ile tutarlı davranışlar sergilemeye zorlayan bir kurallar dizisi olarak kabul edilebilir. Bu yönleriyle değerler örgüt içerisinde yer alan kurallara ve davranış standartlarına anlamlar kazandırarak örgüt karar vericilerini yönlendirirler (Kılıç, 2010, s.83).

\section{Vizyon Bildirgesini Oluşturan Bileşenler}

İşletmeler için faydalı ve işletmeyi başarıya ulaştırabilecek vizyon ifadelerinin önemli bileşenleri içermeleri beklenmektedir. Literatürde bir araştırma yapıldığında iyi ve faydalı bir vizyonun içermesi gereken bileşenleri, Akgemci ve Güleş (2009) bir araya getirerek ifade etmişlerdir. Bu bileşenler;

- İdealist olma,

- Özgün olma,

- Ayrrt Edici Olma,

- Çekici Olma,

- Kisa ve Akılda Kalıcı Olma,

- Gelecek Tanimlayıcı Olma,

- İlham Verici Olması,

Olarak sıralanmıştır. Çalışmada analize konu olan vizyon ifadeleri Akgemci ve Güleş'in (2009) belirlemiş olduğu bileşenlere göre incelenmiştir.

\section{Literatür Taraması}

Literatürde vizyon ifadeleri işletme üzerindeki etkileri bakımından farklı yönlerden incelenmiştir. Ancak vizyon ifadesinin karakteristiği gereği işletmenin uzun dönemli olması, işletme başarısı ve işletme karlılığı gibi özel bağlantıları hakkında da çalışmalara daha sık rastlanmaktadır. Bu çalışmalardan bir kısmı bu bölümde ifade edilmiştir.

Soygür (2018) kamu bankaları ve yerli ve yabancı özel bankaların misyon ve vizyon ifadelerine yönelik bir çalışma yapmıştır. Bu çalışmada, incelemeye dahil edilen bankaların vizyon ve misyon ifadeleri arasında bir farklılık olup olmadığı incelenmiştir. Araştırma sonuçlarına göre kamu bankalarının vizyon ve misyonlarında sektörel liderlik, sosyal sorumluluk 
ve verimlilik kavramlarına ağırlık verildiği görülmüştür. Katılım bankaları da sosyal sorumluluğa önem vermektedir. Yerli sermayeli özel bankaları ise müşteri memnuniyeti ve kaliteye daha fazla önem vermektedir.

Ayhün ve Köse'nin (2018) yaptıkları araştırmada, 10 tane Türk yiyecek ve içecek işletmesi mercek altına alınmıştır. Bu kapsamda, işletmelerin misyon ve vizyon bildirimleri literatürde yer alan özellikleri taşıma durumuna göre değerlendirilmiştir. Misyon ifadelerinde bazı eksikliklerin olduğu tespiti yapılırken vizyon ifadelerinin arzu edilen şekilde oluşturulduğu görülmüştür.

Lamba (2014), yapmış olduğu araştırma kapsamında, 16 Büyükşehir belediyesinin stratejik planlarını misyon, vizyon, temel değerler, stratejik amaçlar ve stratejik hedefler çerçevesinde incelemiştir. Misyon ifadelerinde, yaşam kalitesinde oluşan yükselme, etkili ve verimli bir yönetim anlayışı, planlı bir yönetim, tarihi ve kültürel değerlere sahip çıkma, gibi ifadelerin ön plana çıktığını görmüşlerdir. Vizyon ifadelerine baktıklarında ise tarihi mirasa sahip çıkma, yaşam kalitesindeki artış, yapılan hizmetlerin çevreye saygılı olması, hizmet anlayışı ve hizmet sunumu noktasında öncü bir belediye olabilme ifadelerinin ön plana çıtığını tespit etmişlerdir.

Doğan ve Hatipoğlu'nun (2009) aynı sektörde bulunan ve ölçek olarak birbirlerine benzeyen iki işletmenin vizyon bildirimi yapma ve yapmama durumuna göre ayırdıkları bir araştırma yapmışlardır. Araştırmada vizyon ile işletme başarısı arasındaki ilişki incelenmiştir. Araştırma sonuçlarına göre vizyon bildirimine sahip olan işletmeler, vizyon bildirimine sahip olmayan işletmelere göre 5 kat daha fazla çalışan sayısı artışına, 9 kat daha fazla kar artışına, ortalama cari oranı 7.5 kat fazla ve ortalama aktif kar oranı ise 18 kat fazla olduğu sonucuna ulaşmışlardır.

Akgemci, Çelik ve Ertuğrul'un (2004) Konya Sanayi bölgesinde çalışan 116 yöneticiye uyguladıkları anket ile vizyon ifadesinin olup olmaması ve vizyonun etkileri üzerinde bir araştırma gerçekleştirmişlerdir. Bu araştırma kapsamında, yöneticilerin vizyon ifadesi konusunda bilgi sahibi oldukları ve eğitim ile bilgilerinin artacağı, çoğu işletmede vizyon ifadesinin yer almadığı ve bu kapsamda örgüt yöneticilerine vizyon ifadelerinin değerinin anlaşılması konusunda büyük görevlerin düştüğü sonucuna ulaşılmıştır. 
İnce'nin (2015) yaptığı çalışmada, Türkiye'nin ikinci 500 şirketinin misyon ve vizyon ifadeleri incelenmek istenmiş fakat 305 şirketin misyon ve vizyon ifadesine ulaşılarak çalışma yürütülmüştür. Çalışma sonuçlarına göre, misyon ifadelerinde başarı, yenilikçilik, proaktiflik ve rekabetçilik değerleri ön plana çıkmıştır. Vizyon ifadelerinde ise başarı, yenilikçilik, liderlik ve rekabetçilik kavramlarının ön plana çıkı görülmüştür.

Sabuncuoğlu ve Gök (2008) daha geniş bir perspektif ile hazırladıkları çalışmalarında işletmelerin vizyon ve misyon ifadelerini birlikte değerlendirerek Pazar odaklılık konusuna yönelmişlerdir. Bu kapsamda, Türkiye'nin 500 büyük firmasının 245 tanesinin misyon veya vizyonları incelemeye alınmıştır. Elde edilen bulgulara göre temel alınan ortak noktanın faaliyet içerisinde bulundukları sektörün kaynaklarının verimli kullanılarak müşteri istek ve beklentilerinin üst düzeyde karşılanabilmesi hedeflenmiştir.

Ay ve Koca'nın (2012) ISO 500 listesinde 2009 yllında yer alan firmaların, misyon, vizyon ve değerleri içerik analizine tabi tutulmuştur. elde edilen bulgulara göre misyon açılamalarında ağırlıklı olarak sosyal sorumluluk, yenilikçilik, kalite ve ekonomi, vizyon ifadelerinde, liderlik, yenilikçilik ve küresellik, değerlerde ise, hümanist ve davranışsal değerlerin ağırlıklı olduğu görülmüştür. Son olarak elde edilen bulguların küresel şirketlerde de ortak paydalarda buluştuğu ifade edilmiştir.

Papatya (1998) işletmelerin vizyon oluşturmada izlemeleri gereken yolları derlediği makalesinde vizyon ifadesinin oluşturulma sürecinde tek bir yolun olmadığı, fakat çalışanlarla beraber hazırlamanın uygun olduğu görüşüne ulaşmıştır. Bu şekilde hazırlanmadığı ve sadece sözlerle kısıtlı kaldığı zaman gelecekte yön gösterme gibi katkılarının olmayacağına vurgu yapılmıştır.

Ocak, Güler ve Basım'ın (2016) Türk Savunma Sanayi firmalarının misyon ve vizyonlarına yönelik olarak gerçekleştirdikleri araştırmada, bu firmaların misyon ve vizyon ifadelerinde hangi öğelerin kullanıldığ 1 ve bu ifadelerin ulusal savunma sanayi yönlendirici dokümanları ile uyumu araştırılmıştır. Bu kapsamda 87 vizyon ve 79 misyon ifadesi incelemeye alınmıştır. Çalışmanın sonucuna göre misyon ifadelerinde 13 öğe ve vizyon ifadelerinde ise 14 öğe kullanılmıştır. Ayrıca savunma sanayi firmalarının bir kısmının vizyon ve misyon ifadelerinin stratejik öneminin farkında olduğu sonucuna ulaşılmıştır. 


\section{Araştırma}

\section{Araştırmanın Amacı}

Stratejik yönetim içerisinde yer alan stratejik ifadeler işletmelerin performanslarını artırabilmeleri ve uzun ömürlü bir yaşam sürebilmeleri için önemli görülen değerlerdir. Bu kapsamda, vizyon ifadeleri de bir işletmenin performansı, başarısı, uzun ömürlülüğü ve karlılığı üzerinde önemli etkileri olan değerlerden biridir. Vizyon ifadesinin ortaya koyduğu önemli değerlerin bütün çalışanlar tarafından kabul görmesi ve özümsenmesi örgütün geleceğe yönelik olarak belirlediği hedeflere daha kolay ulaşabilmesine yardımcı olacaktır. Örgütün hedeflerinin çalışanlara duyurulabilmesinin en etkili ve uygun yöntemi vizyon ifadesinin çalışanlara özümsetilmesidir. Özellikle rekabet avantajı, uzun ömür ve ortalamanın üzerinde karlılık gibi ana hedeflerin gerçekleştirilmesinde vizyon ifadesi aracı rol oynayabilir.

Bu çalışmanın temel amacı vizyon ifadesi ile karlılık arasında bir bağın olması durumunu incelemektir. Bu kapsamda işletmelerin vizyon ifadelerinin literatürde yer alan değerleri hangi oranlarda barındırdıkları incelenmiştir. Yapılan çalışmada karlılık ile vizyon ifadesi odak noktasına alınmıştır. Aynı zamanda vizyon ifadelerinin eksikleri de ortaya konmaya çalışılmıştır.

\section{Araştırmanın Yöntemi}

Araştırmada birincil ve ikincil veriler birlikte kullanılmıştır. Araştırmanın verilerinin sağlandığı vizyon ifadeleri şirketlerin internet sitelerinden halka açık olarak sundukları alanlardan temin edilmiştir. Araştırmada nitel analiz yöntemi uygulanmıştır. İslamoğlu'nun (İslamoğlu, 2011) tanımlamasına göre nitel analiz; "sosyal olguları bağlı oldukları ve içinde yer aldıkları ortamda doğal görünümleriyle gözlem, görüşme ya da belgeleri değerlendirmek yoluyla bilgi edinme ve bu bilgileri analiz ederek kuram geliştirme" dir. Nitel analiz, nicel analizin hep aynı gözle görme idealinden farklı olarak daha dinamik bir yaklaşım tarzı olarak kabul edilebilir. Nitel analizin en önemli avantajı bireyin bakış açısının da etkili olmasıdır (İslamoğlu, 2011, s.186). Nitel analiz yöntemleri arasından da içerik analizi 
yöntemi uygulanmıştır. İçerik analizi yöntemi ile ilk bakışta görülemeyecek olan gizlenmiş farklı yapıların gözlemlenmesi amaçlanmaktadır. İçerik analizinde incelemeye alınan dokümanlar incelenerek araştırılan birimlerin doküman içerisinde yer alıp almaması durumu belirlenmeye çalışılmaktadır (Kurtuluş, 2010, s.50,51).

Araştırma kapsamında işletmelerin vizyon ifadeleri Akgemci ve Güleş'in (2009) bir vizyon ifadesinde yer alması gereken unsurlar olarak belirlediği 7 kriter çerçevesinde içerik analizine tabi tutulmuştur. Analizler iki araştırmacı tarafından yapılmıştır. İçerik analizi konusunda uzman olan iki araştırmacı farklı zamanlarda ve ikişer defa vizyon ifadelerini okuyarak, belirlenen kriterlerden barındıran vizyon ifadelerinin karşısına $(+)$ işareti, kriteri barındırmayan vizyon ifadelerinin karşısına ise (-) işareti konularak bir kotlama yapmıştır. Elde edilen veriler daha sonra yazar tarafından değerlendirilmiştir. Belirlenen kriterlerin varlıklarının tespiti için Latif ve Muslu'nun (2015) belirlediği 7 soru, vizyon ifadelerine araştırmac1 tarafından uygulanmış ve elde edilen veriler analize tabi tutulmuştur. $\mathrm{Bu}$ sorular şunlardır (Latif \& Muslu, 2015, s.18);

- "İdealist: İşletmenin temel amaç ve hedefleri var mıdır?

- Özgünlük: İşletme, kendine özgü değerlere sahip midir?

- Ayırt edicilik: İşletme vizyonu, ayırt edici özelliğe sahip midir?

- Çekicilik: İşletme iç ve diş ortaklarının ilgisini çekmekte midir?

- Kısa ve Akılda Kalıcılık: İşletme, vizyonunu tüm paydaşlarına iletebiliyor mu?

- İlham verici ve İddialılık: İşletme çalışanlarına ilham vermekte midir?

- Gelecekteki Başarı ve İdealler: İşletmenin tasarlanmış bir gelecek planı var mıdır?"

\section{Araştırmanın Evreni}

Araştırmanın evrenini Fortune Turkey dergisinin 08/02/2019 tarihinde yayınladığ1 "20 yıldır kar açıklayan şirketler" başlıklı haberinde yer alan 19 firma oluşturmaktadır. Bu firmalar Borsa İstanbul'da işlem gören ve habere göre son 20 yılda hiç zarar açılamayıp her yıl kar açıklayan işletmelerdir(Fortune, 2019). Bu listedeki işletmelerin vizyon ifadelerine yönelik bir analiz yapılmıştır. Yapılan incelemeler sonucunda evrende yer alan 19 
işletmenin hepsinin vizyon ifadelerinin bulunduğu görülmüş, bu sebeple bütün işletmeler analiz kapsamına alınmıştır.

\section{Araştırmanın Kisıtları}

Araştırma, sadece Fortune Turkey dergisinde yer alan habere konu olan 20 yıldır kar açıklayan 19 firmaya uygulanmıştır. Bunun yanında kar açıklamamış firmaların vizyon ifadeleri ile karşılaştırmalı bir analiz yapılmaması büyük bir kısıt olarak kabul edilebilir. Aynı zamanda vizyon ifadelerine yönelik içerik analizi yanında gözlem gibi etkileşimli sonuçların elde edilebileceği yöntemler kullanılarak daha kapsamlı sonuçlara ulaşılabilmesi de diğer bir kısıt olarak düşünülebilir. Belirtilen kısıtlar dikkate alınarak daha geniş çaplı ve daha net sonuçlara ulaşılabilecek analizler uygulanabilir.

\section{Araştırmanın Güvenilirliği}

Araştırmanın güvenilirliğini kontrol etmek amacıyla kappa testi uygulanmıştır. Kappa katsayısı "kategorik maddelerin değerlendirilmesinde iki gözlemci arasındaki uyumu ölçen istatistiktir" (Kılıç, 2015, s.142).Kappa testinin formülü şu şekildedir.

$$
\kappa=\frac{\operatorname{Pr}(\mathbf{a})-\operatorname{Pr}(e)}{1-\operatorname{Pr}(e)}
$$

- $\operatorname{Pr}(\mathrm{a})$ : iki değerlendirici için gözlemlenen uyumların toplam orantısı

- $\operatorname{Pr}(\mathrm{e})$ : bu uyumun şansa bağlı ortaya çıkma olasılığ1

Yapılan incelemelerde iki gözlemcinin $\operatorname{Pr}(\mathrm{a})$ değeri 0,900, $\operatorname{Pr}(\mathrm{e})$ değeri ise 0,630 çıkmıştır. Bu şekilde formül oluşturulduğunda Kappa katsayısı, 0,729 olarak hesaplanmıştır. Kılıç’1n (Kılıç S. , 2015) belirttiğine göre kappa sayısının 0,61 ile 0,80 arasında çıkması gözlemcilerin arasında iyi düzeyde bir uyumun olduğunu göstermektedir. Bu sonuç çalışmanın güvenilirliğini göstermektedir (Kılıç, 2015, s.143). 


\section{Bulgular}

Bu kısımda araştırmaya dahil edilen firmaların özellikleri ve vizyon ifadelerinin kapsadığı değerler ile ilgili bilgiler paylaşılmıştır. Araştırma kapsamına Fortune Turkey dergisinin yapmış olduğu haberdeki 19 firma dahil edilmiştir. Bu firmaların sektörel dağılımları Tablo 1'de yer almaktadir.

Tablo 1. Firmaların Sektörel Dağılımları (Fortune, 2019)

\begin{tabular}{lll}
\hline Firmanın Yer aldığı Sektör & Firma Sayısı & Yüzde Değeri \\
\hline Bayındırlık ve İmar & 1 & 5,26 \\
\hline Cam & 1 & 5,26 \\
\hline Çimento ve Beton & 7 & 36,84 \\
\hline Dayanıklı Tüketim & 2 & 10,53 \\
\hline Diğer Kimyevi Ürünler & 1 & 5,26 \\
\hline Kağıt Ürünleri & 1 & 5,26 \\
\hline Kırtasiye & 1 & 5,26 \\
\hline Orman Ürünleri ve Mobilya & 1 & 5,26 \\
\hline Otomotiv Yan Sanayi & 1 & 5,26 \\
\hline Petrol & 1 & 5,26 \\
\hline Sigorta Şirketleri & 1 & 5,26 \\
\hline Ulaştırma & 1 & 5,26 \\
\hline Toplam & $\mathbf{1 9}$ & $\mathbf{1 0 0}$
\end{tabular}

Tablo 1'de yer alan bilgilere göre son 20 yıldır aralıksız kar açıklayan firmaların 7 tanesi $(\% 36,84)$ çimento sektöründe yer almaktadır. Toplam firmaların \% 10,53'ünü oluşturan 2 firma ise dayanıklı tüketim sektöründe yer almaktadır. Diğer firmalar ise bayındırlık, cam, Diğer kimyevi ürünler, kağıt ürünleri, kırtasiye, orman ürünleri ve mobilya, otomotiv yan sanayi, petrol, sigorta şirketleri ve ulaştırma sektöründe 1 firma olarak dağılım göstermektedir. Burada çimento sektöründe yer alan firma sayısının çokluğu dikkat çekmektedir.

Firmaların kuruluş tarihleri karlılık ve uzun ömürlülük ilişkisinde önemli bir değer oluşturmaktadır. Bu sebeple araştırmaya dahil edilen firmaların kuruluş yılları da kronolojik bir sıralamaya alınmıştır. Tablo 2' de bu sıralama yer almaktadır. Bu verilerin yanında bilgilerin elde edildiği ilgili firma web siteleri de tabloda yer almaktadır. 
Tablo 2: Firmaların Kuruluş Yıllarına Göre Dă̆ılımı Tablosu

\begin{tabular}{llll}
\hline Yillar & Firma Sayıs & Firma Adı & Web Sitesi Adresi \\
\hline 1948 & 1 & Alkim Kimya & $\underline{\text { http://www.alkim.com }}$ \\
\hline \multirow{2}{*}{1954} & 3 & Adana Çimento & $\underline{\text { http://www.adanacimento.com.tr }}$ \\
\cline { 3 - 4 } & & Konya Çimento & $\underline{\text { http://www.konyacimento.com.tr }}$ \\
\cline { 2 - 4 } & Alarko Carrier & www.alarko-carrier.com.tr \\
\hline 1955 & 1 & Arçelik & www.arcelik.com.tr \\
\hline 1957 & 2 & Enka İnşaat & www.enka.com \\
\cline { 2 - 4 } & 1958 & Anadolu Cam & $\underline{\text { www.anadolucam.net/ }}$ \\
\hline 1961 & 1 & Çelebi & $\underline{\text { http://www.celebi.com.tr }}$ \\
\hline 1966 & 2 & Aygaz & www.aygaz.com.tr \\
\hline 1967 & 2 & Bursa Çimento & www.bursacimento.com.tr \\
\cline { 2 - 4 } & Nuh Çimento & www.nuhcimento.com.tr \\
\hline 1969 & 2 & Bolu Çimento & $\underline{\text { http://www.bolucimento.com.tr }}$ \\
\cline { 2 - 4 } & Kartonsan & $\underline{\text { http://www.kartonsan.com.tr }}$ \\
\hline 1974 & 1 & Mardin Çimento & $\underline{\text { http://www.mardincimento.com.tr }}$ \\
\hline 1978 & 1 & Adel Kalemcilik & www.adel.com.tr \\
\hline 1990 & 1 & Brisa & $\underline{\text { http://www.brisa.com.tr }}$ \\
\hline 1996 & 1 & Gentaş & $\underline{\text { www.gentas.com.tr/ }}$ \\
\hline & & Anadolu Hayat Emek. & www.anadoluhayat.com.tr \\
\hline
\end{tabular}

Tablo 2 verilerine göre en eski firma şu anda 71 yaşında olan Alkim Kimya firmasıdır ve 1948 yılında kurulmuştur. En yeni firma ise 1996 y1lında kurulmuş olan Akçansa Çimento Firmasıdır ve şu anda 23 yaşındadır. 1950-1959 yılları arasında 7 firma kurulmuştur. 1960-1969 yılları arasinda 7 firma kurulmuştur. 1970-2000 yılları arasında ise 4 firma kurulmuştur.

Araştırmaya dahil edilen işletmelerin son on yılda (1998-2017 yılları arası) Net karlarının kaç kat arttığı Tablo 3'de gösterilmektedir.

Tablo 3 verilerine göre en yüksek artışı kaydeden firmanın 1247,02 kat artış ile Enka İnşaat olduğu görülmektedir. Bu değeri 1043,02 kat artışla takip eden firma da Anadolu Cam olmuştur. En düşük kar artışını gerçekleştiren firmalar ise 8,40 kat artış ile Kartonsan ve 9,90 kat artış ile Alarko Carrier firmalarıdır. Sektörel olarak en yoğun firma sayısına sahip olan çimento sektöründe ortalama 21,07 kat kar artışı gerçekleşmiştir $(147,5 / 7)$. 
Tablo 3: Firmaların Net Kar Artışı Tablosu

\begin{tabular}{llll}
\hline FíRMA ADI & $\begin{array}{l}\mathbf{1 9 9 8 / 1 2} \mathbf{N E T} \\
\text { KAR (TL) }\end{array}$ & $\begin{array}{l}\text { 2017/12 NET } \\
\text { KAR (TL) }\end{array}$ & $\begin{array}{l}\text { KAÇ KAT } \\
\text { ARTTI? }\end{array}$ \\
\hline Enka İnşaat & 2.059 .098 & 2.567 .736 .000 & $1.247,02$ \\
\hline Anadolu Cam & 173.771 & 181.317 .000 & $1.043,42$ \\
\hline Adana Çimento & 552.239 & 12.597 .246 & 22,81 \\
\hline Akçansa & 9.585 .612 & 148.693 .675 & 15,51 \\
\hline Bolu Çimento & 3.388 .917 & 116.820 .407 & 34,47 \\
\hline Bursa Çimento & 4.065 .625 & 71.221 .773 & 17,52 \\
\hline Konya Çimento & 1.965 .701 & 41.923 .047 & 21,33 \\
\hline Mardin Çimento & 2.898 .234 & 5.219 .071 & 18,19 \\
\hline Nuh Çimento & 8.485 .294 & 149.907 .991 & 17,67 \\
\hline Alarko Carrier & 5.231 .073 & 51.791 .034 & 9,90 \\
\hline Arçelik & 25.646 .628 & 842.949 .000 & 32,87 \\
\hline Alkim Kimya & 384.537 & 63.598 .382 & 165,39 \\
\hline Kartonsan & 4.573 .759 & 38.426 .713 & 8,40 \\
\hline Adel Kalemcilik & 1.088 .977 & 26.870 .000 & 24,67 \\
\hline Gentaş & 1.343 .465 & 31.242 .377 & 23,26 \\
\hline Brisa & 11.896 .569 & 95.203 .492 & 8,00 \\
\hline Aygaz & 9.420 .983 & 577.019 .000 & 61,25 \\
\hline Anadolu Hayat Emek. & 7.273 .540 & 224.702 .693 & 30,89 \\
\hline Çelebi & 1.127 .945 & 85.361 .608 & 75,68
\end{tabular}

Vizyon bildirimleri ile ilgili olarak yapılan analizin sonuçları tablo 4'de yer almaktadir.

Tablo 4 incelendiğinde çoğu firmanın araştırmaya dahil olan firmaların vizyon ifadelerinde kriter olarak belirlenen 7 değerin çoğunluğunun yer aldığı görülebilir. Bütün firmaların en az 4 özelliği barındıran vizyon ifadesine sahip olduğu görülmektedir. Bu durum vizyon ifadesinin belirlenen kriterlere göre düzenlenmiş olan firmaların başarılı firmalar olabileceğine dair önemli bir kanıt gösterebilmektedir. Ayrıca çok tercih edilen değerlerden olan gelecek tanımlayıcılık ve idealist olma vizyon ifadesinin ruhuna uygun olduğunu göstermektedir. Daha ayrıntılı bakış açısına sahip olmak adına, vizyonlarda yer alan özelliklerin sayısına göre oluşturulmuş dağılımın yer aldığ 1 tablo 5'e bakmakta fayda vardır. 
Tablo 4. Firmaların Vizyon İfadelerinin Özelliklere Dă̆ılımı Tablosu

\begin{tabular}{|c|c|c|c|c|c|c|c|c|}
\hline & $\begin{array}{l}\text { İdea- } \\
\text { list }\end{array}$ & $\begin{array}{l}\text { Öz- } \\
\text { gün- } \\
\text { lük }\end{array}$ & $\begin{array}{l}\text { Ayırt } \\
\text { Edici- } \\
\text { lik }\end{array}$ & $\begin{array}{l}\text { Çe- } \\
\text { kici- } \\
\text { lik }\end{array}$ & $\begin{array}{l}\text { Kisa- } \\
\text { lik }\end{array}$ & $\begin{array}{l}\text { Illham } \\
\text { Verici- } \\
\text { lik }\end{array}$ & $\begin{array}{l}\text { Gelecek } \\
\text { Tanımla- } \\
\text { yıcı }\end{array}$ & Toplam \\
\hline Enka İnşaat & + & - & - & + & + & + & + & 5 \\
\hline Anadolu Cam & + & - & - & + & + & + & + & 5 \\
\hline Adana Çimento & + & + & - & + & + & + & + & 6 \\
\hline Akçansa & + & - & + & + & - & + & + & 5 \\
\hline Bolu Çimento & + & + & - & + & + & + & + & 6 \\
\hline Bursa Çimento & + & - & + & + & + & + & + & 6 \\
\hline Konya Çimento & + & + & + & + & - & + & + & 6 \\
\hline Mardin Çimento & + & + & - & + & + & + & + & 6 \\
\hline Nuh Çimento & + & - & + & + & + & + & + & 6 \\
\hline Alarko Carrier & + & + & + & - & + & + & + & 6 \\
\hline Arçelik & + & + & + & - & + & - & - & 4 \\
\hline Alkim Kimya & + & + & + & - & - & - & + & 4 \\
\hline Kartonsan & - & + & - & + & + & - & + & 4 \\
\hline Adel Kalemcilik & + & - & + & - & + & + & + & 5 \\
\hline Gentaş & + & - & - & - & + & + & + & 4 \\
\hline Brisa & + & + & - & - & + & - & + & 4 \\
\hline Aygaz & + & + & + & - & + & - & + & 5 \\
\hline $\begin{array}{l}\text { Anadolu Hayat } \\
\text { Emeklilik }\end{array}$ & + & + & - & - & + & + & + & 5 \\
\hline Çelebi & + & + & - & - & - & + & + & 4 \\
\hline TOPLAM & 18 & 12 & 9 & 10 & 15 & 14 & 18 & \\
\hline
\end{tabular}

Kaynak: Vizyon Ífadeleri Adı Geçen İşletmelerin Kamuya Açık İnternet Sitesi

Tablo 5. Firmaların Vizyonlarının Sahip Olduğu Özellik Dağılımı

\begin{tabular}{lll}
\hline Özellik Sayısı & Firma Sayısı (n) & Yüzde (\%) \\
\hline 1 & - & - \\
\hline 2 & - & - \\
\hline 3 & - & - \\
\hline 4 & 6 & 31,58 \\
\hline 5 & 6 & 31,58 \\
\hline 6 & 7 & 36,84 \\
\hline 7 & - & - \\
\hline Toplam & $\mathbf{1 9}$ & $\mathbf{1 0 0}$ \\
\hline
\end{tabular}

Tablo 5'e göre işletmelerin vizyon ifadelerinde en az 4 değerin yer aldığ 1 görülmektedir. 4 değere sahip olan işletme sayısı 6, 5 değere sahip olan işletme sayısı 6, 6 değere sahip olan işletme sayısı 7'dir. Ancak bütün değerleri barındıran vizyon ifadesi bulunamamıştır. Bu durum vizyon ifadelerinin hala geliştirilmeye ihtiyacının olduğunu göstermektedir. Ancak 
başarı ile ilişkilendirildiğinde vizyon ifadelerinin literatürdeki kriterlerin çoğuna sahip olması yönüyle başarılı şirketlerde olan yapılara uygun olduğu düşünülebilir. Vizyon ifadelerinde yer alan kriterlerin toplamdaki durumuna bakmak için ise tablo 6 oluşturulmuştur.

Tablo 6. Vizyonlardaki Kriterlerin Seçim Sıklığı Tablosu

\begin{tabular}{lll}
\hline Özellik & Seçim Sayısı (n) & Yüzde (\%) \\
\hline İdealist & 18 & 18,8 \\
\hline Özgünlük & 12 & 12,5 \\
\hline Ayırt Edicilik & 9 & 9,4 \\
\hline Çekicilik & 10 & 10,4 \\
\hline Kisalık & 15 & 15,6 \\
\hline İham Vericilik & 14 & 14,6 \\
\hline Gelecek Tanımlayıcı & 18 & 18,8 \\
\hline Toplam & $\mathbf{9 6}$ & $\mathbf{1 0 0}$ \\
\hline
\end{tabular}

Tablo 6 incelendiğinde vizyon ifadelerinde en çok yer alan kriterin idealist ve gelecek tanımlayıcılık olduğu görülmektedir. Bu durum vizyon ifadesinin genel karakteristiğinin yansıtıldığı anlamını taşımaktadır. Ayrıca amaç ve hedefleri belirten bir yapıda olan vizyonlarında çoğunlukta olduğu görülmektedir. 15 işletmenin vizyon ifadesinin beklendiği üzere kısa ve anlaşılır olduğu anlaşılmaktadır. 14 işletmenin vizyon ifadesi ilham verici yapı taşımaktadır. 12 işletmenin vizyon ifadesi özgün bir yapıya sahipken 10 işletmenin vizyon ifadesi de çekici bir düzendedir. En az yer alan kriter olan ayırt edicilik özelliği 9 işletmenin vizyon ifadesinin bir özelliği olarak belirlenmiştir. Bu durum vizyon ifadelerinin daha spesifik ve işletmenin kendine has yetkinlik (competence) ve yeterliliklerinin daha fazla yansıtıldığı bir yapıya dönüşümünün ihtiyacını gözler önüne sermektedir.

\section{Tartışma ve Sonuç}

Vizyon ifadesi stratejik yönetimin önemli bir unsuru olarak kabul edilmektedir. İşletmenin geleceğe yönelik olarak tasarladığı amaç ve hedeflerin bir ürünü olarak meydana gelmektedir. Bu sebeple vizyon ifadesi esasen işletmenin kendine biçtiği ömür, karlılık oranı ve başarı düzeyi olarak kabul edilebilir. İşletmeleri vizyon ifadelerini paydaşları ile paylaşarak 
onlarla oluşan ilişkilerini de vizyon ifadeleri çerçevesinde geliştirdiklerinde başarılık bir yapı olabilmektedir. Bu sebeple vizyon ifadesinin bazı özellikleri taşıması ve paydaşlarla ortak bir bakış açısı oluşturması büyük önem taşımaktadır.

Çalışmada, 20 yıldır artarda kar açıklayan işletmelerin vizyon ifadeleri incelenmiş ve işletme karlılığı ve başarısı ile vizyon ifadesinin arsındaki ilişkiler belirlenmek istenmiştir. Elde edilen bulgulara göre işletmelerin vizyon ifadelerinde en dikkat çeken özellikler idealist, gelecek tanımlayıı, kısa ve ilham verici olmalarıdır. Bu sonuç literatürde istenen bir yapı oluşturmaktadır. Çalışmada ulaşılan sonuçlar, Erden Ayhün ve Çavuşgil Köse'nin (2018) ve İnce'nin (2015) ulaştı̆̆1 sonuçlarla paralellik göstermektedir. Özellikle karlılık ve vizyon ifadeleri arsındaki ilişkiye odaklanmış bir çalışma olan Doğan ve Hatipoğlu'nun (2009) elde ettiği bulgular 1ş1ğında ulaşılan sonuçta vizyon sahibi olan işletmelerin aktif karlılık oranlarının vizyon sahibi olmayan diğer işletmeye oranla 18 kat daha fazla olması, bu çalışmanın ulaştığı sonuçları destekler nitelikte kabul edilebilir. Bu çalışmada da ele alınan şirketler 1998-2018 döneminde en az 8 en yüksek ise 1247 kat karlılık artışı gerçekleştirmişlerdir. Bu sonuçlar literatür ile paralellik göstermektedir.

Araştırmaya dahil edilen işletmelerin vizyon ifadelerinin taşıdığı özelikler dikkate alınarak vizyonun temel amacı olan uzun ömürlü olmak, karlılık ve işletme başarısının vizyon ifadelerinde de yansıtıldığını düşünmek yanlış olmayacaktır. Bu sebeple vizyon ifadelerinin taşıdığ özellikler ile başarı arasında büyük bir ilişkinin olduğu sonucuna ulaşılabilir.

Araştırmanın verilerine göre işletmelere bazı önerilerde bulunmak gerekmektedir. Bu öneriler şunlardır:

- İşletmelerin literatürde yer alan özelliklere göre vizyon ifadelerini revize edip kendi amaç ve hedefleri doğrultusunda ancak kendilerine özgü bir yapıda vizyon ifadeleri oluşturmaları başarılarına daha büyük katkı sağlayabilecektir.

- Çekicilik ve ayırt edicilik özelliklerine daha dikkatle yaklaşıp spesifik özellikler taşıyan vizyon ifadeleri daha yüksek katkı sağlayacaktır.

- Vizyon ifadesi bütün çalışanlar arasında anlaşılmalı ve çalışmaların tamamının vizyon ifadesinde oluşturulan kültür çerçevesinde gerçekleştirilmelidir. Bu yol ile daha hızlı ilerleme 
gerçekleşebilecektir. Özellikle Türkiye'nin sanayi görüntüsü dikkate alındığında işletmelere daha fazla sorumluluk düşmektedir. Gerek istihdam gerekse kaliteli üretim konusunda başarılı adımlar atabilmek için stratejik yönetim ve özellikle vizyon ifadesi büyün önem taşımaktadır.

Sonuç olarak bakıldığında çalışma kapsamına alınan firmaların özel durumu vizyon ifadelerinin kalitesinin yüksek olmasının en önemli sebebidir. Uzun ömürlü olan ve uzun yıllardır kar açıklayan firmaların vizyon ifadelerinin literatürde belirtilen kriterlerin çoğuna sahip olması beklenen bir durum olsa da diğer şirketlere katkısı boyutuyla incelendiğinde burada ifade edilen özelliklerin başarılı olmayı ve karlılığı hedefleyen diğer işletmelere de birer yol haritası oluşturması açısından önem kazanmaktadır. Vizyon ifadesinin kapsamı ne oranda genişler ve literatürde belirtilen kriterlere uyum gösterilirse uzun vadeli ömür, işletme başarısı ve işletme karlılığı düzeylerinde artışlar olması beklenilen bir durum olarak kabul edilebilir. Gelecekte yapılacak olan çalışmalarda sadece vizyon ifadesi değil stratejik yönetimin diğer önemli unsurları olan misyon ifadesi, amaçlar ve değerler de dahil edilerek daha kapsamlı çalışmaların yapılması daha doğru sonuçların ortaya çıkmasına zemin hazırlayacaktır. Ayrıca işletmelerin sektörel bazda dağılımlarının da sağlıklı bir şekilde dağılım gösterebileceği işletmelerin vizyon ifadelerinin test edilmesi de daha farklı sonuçlara ulaşmada yardımcı olacaktır. 
EXTENDED ABSTRACT

\title{
Strategic Perspective on The Relationship Between Company Profitability and The Vision of The Company: A Review on BIST Companies
}

\author{
Safa Acar
}

Siirt University

Strategic management is a management style that provides a number of benefits that will help businesses look to the future with confidence. For this reason, businesses with long-lasting goals, expecting high profitability rates and wanting to increase their performance level, focus on these studies. Increasingly competitive market structure in recent years necessitates enterprises to be ahead of their competitors. For this reason, businesses should stay one step ahead of their competitors and align their businesses with strategic management practices.

Businesses that are forced to work in an intense competitive environment apply various methods with a long life expectancy, achieving a sustainable competitive advantage and expecting a profit above the sector average. One of the most interesting of these practices in recent years is the strategic management practices and the elements evaluated within this scope. Thanks to strategic management, a long-lasting profitable and competitive advantage can be realized. In this context, businesses have started to work in this direction by showing improvements in every field since the beginning of their lives. The activities that enterprises create for the future such as longevity and profitability can be implemented within the scope of strategic management. Of these elements, which are evaluated within the scope of strategic management, is the expression of vision, which includes future-oriented statements. There are many studies in the literature about the effect and contribution of vision expression on business performance (Akgemci, Çelik, ve Ertuğrul, 2004; Doğan ve Hatipoğlu, 2009; Özer, 2010; Karaman, 2005). 
The main purpose of this study is to determine the strategic direction of the relationship between profitability and vision. In this context, it is aimed to determine the relationships between the profitability and the success of the companies that are traded in Borsa İstanbul and have been making profit for the last 20 years and the vision statements they have created and shared with their stakeholders. vision statements of the company, previously identified in the literature, categorized before According to avoid incorporating the elements of a successful vision should be subjected to a general analysis.

Looking at the business literature, it is seen that there are many definitions of vision expression and each of these definitions touch different points. In general, the expression of vision can be defined as an expression of the point that the enterprise voluntarily determines and wishes to see itself in the future. Within this framework, the vision expression is the whole of the dreams and targets about the enterprise which occurs only in the minds of managers rather than covering all employees (İnce, 2015, p.146).

The expression of vision can be regarded as a foresight, a designed image of the future, a picture for the future, or an ideology. In this context, it can be thought of as an imagination that cannot be drawn. For the organization, the expression of vision indicates a direction that has become more general and abstract than a dream. A company that constitutes a vision statement has established a bridge to the future (Duman, 2007, p.5,6).

The vision expression of a business is the most basic indicator of the values and goals of its objectives. It is a way of addressing the feelings and thoughts of the business. In this context, values, goals and objectives are the main components of a vision. Businesses should express their vision in the form of a catchword in order to see the benefits of vision. It is possible to come across different vision expressions in every society because the social values that each business is in have an effect on the vision (Soygür, 2018, p.989).

According to Ülgen and Mirze (2013), the expression of vision is expressed as an imagination or a dream about a desired situation to be achieved or to be achieved in the future. In other words, a vision is defined as a photograph or a picture of the future situation of an enterprise or an 
individual. Vision is a very important starting point in strategic management. With the expression of vision, businesses can establish their goals and objectives (Ülgen ve Mirze, 2013, p. 177).

The vision statement serves as a guide for the employees about the future of the business. It also provides the investors with the guiding principles of what steps they should take in achieving the targets set in the future. Through the expression of vision, the employees of the enterprise are directed to the objectives of the enterprise and prevent the employees from doing inefficient works. It is no different from a ship trying to move at sea without a vision route without an operational route. When there is a vision in the business, the company moves towards cooperation, innovation and rational behavior. However, a company that does not have a vision expression moves towards failure, incompetence and chaos (Ülgen ve Mirze, 2013, p.178).

When the features of the vision statement are considered, the vision statement should be realistic, be applicable, activate all business systems, be a mirror to the goals as a source of inspiration for the working individuals, provide organizational commitment, direct the enterprise to the future in the best possible time. individuals need to focus their attention on the focal point, transform the objectives and strategies of the business, give direction understanding, be supported by senior management and add a vision to individuals (Akgemci, Çelik, ve Ertuğrul, 2004, p.4).

It is expected that vision statements that are useful for businesses and that will make the business successful will contain important components. When a research is made in the literature, Akgemci and Güleş (2009) put together the components that should include a good and useful vision. These components;

- Being an idealist,

- Being original,

- Being Distinguished,

- Being Attractive,

- Being Short and Permanent,

- Being Future Descriptive,

- Being Inspirational,

As listed. 
The expression of vision is accepted as an important element of strategic management. It is produced as a product of the aims and targets designed by the company for the future. For this reason, the expression of vision can be accepted as the life expectancy, profitability rate and success level.

In this study, the vision statements of the companies that have been announcing profits for 20 years have been examined and the relationships between the profitability and success of the company and the vision statement have been determined. According to the findings, the most striking features of the companies' vision statements are that they are idealistic, future descriptive, short and inspiring. This result is a desirable structure in the literature.

The results of the study are in line with the results of Erden Ayhün and Çavuşgil Köse (2018) and İnce (2015). In the light of the findings obtained by Doğan and Hatipoğlu (2009), which is a study focused on the relationship between profitability and vision expressions, the fact that acceptable the active profitability ratios of the visionary enterprises is In this study, 18 times higher than the non-visionary company supports the results of this study the companies that were discussed in the period of 1998-2018 increased at least 8 and increased the profit by 1247 times. These results are in line with the literature.

According to the data of the research, some suggestions should be made to the enterprises. First of all, the revision of the vision statements according to the characteristics in the literature and creating a vision statement in line with their own aims and objectives will create a greater contribution to their success. Vision expressions with specific features will contribute more closely to attractiveness and distinctiveness. The expression of vision should be understood among all employees and all activities should be carried out within the framework of the culture created in the vision statement. This way, faster progress can be achieved. Especially when considering Turkey's industrial image is reduced more responsibility to the company. Strategic management and especially the expression of vision is of utmost importance in order to take successful steps in both employment and quality production. 
As a result, the special situation of the companies included in the study is the most important reason for the high quality of vision statements. Although it is expected that the vision statements of long-lasting and longlasting companies will have many of the criteria mentioned in the literature, when they are examined in terms of their contribution to other companies, the features expressed here are important in terms of being successful and creating a roadmap for other companies aiming at profitability.

\section{Kaynakça / References}

Akgemci, T., ve Güleş, H. K. (2009). İşletmelerde stratejik yönetim. Ankara: Gazi Kitabevi.

Akgemci, T., Çelik, A., ve Ertuğrul, Ü. G. (2004). Vizyon sahibi örgütlerin özellikleri: Konya sanayi işletmelerinde yapılan bir araştırma. Selçuk Üniversitesi Soyal Bilimler Dergisi, 11, 1-28.

Aktan, C. C. (2019, 02 16). Organizasyonlarda misyon, vizyon ve değerler ve ahlak bildirgelerinin oluşturulmast için değişim ilkeleri. 02 16, 2019 tarihinde http://www.canaktan.org: http://www.canaktan.org/yonetim/yeni-yonetim/vizyon-yonetimi.htm adresinden alındı

Ay, Ü., ve Koca, A. İ. (2012). Iso 500 listesindeki işletmelerin misyon, vizyon ve değerlerinin içerik analizi. Organizasyon ve Yönetim Bilimleri Dergisi, 4(2), 201-210.

Bircan, İ. (2002). Kamu kesiminde stratejik yönetim ve vizyon. Planlama Dergisi, Özel Sayı, 11-19.

Collins, J. C., ve Porras, J. I. (1991). Organizational vision and visionary organization. California Management Review, 34(1), 30-52.

Çetin, S. (2009). Vizyon yönetimi. Selçuk Üniversitesi Sosyal Bilimler Enstitüsü Dergisi, 22, 95-103.

Doğan, S., ve Hatipoğlu, C. (2009). Küçük ve orta boy işletmelerde vizyon açıklamasının işletmenin performansına etkisine ilişkin bir araştırma. Atatürk Üniversitesi İktisadi ve İdari Bilimler Dergisi, 23(2), 81-99.

Duman, M. (2007). Kentsel vizyon: İstanbul Büyükşehir Belediyesi örneği. Yüksek Lisans TeziGazi Üniversitesi, Sosyal Bilimler Enstitüsü, Kamu Yönetimi Anabilim Dalı, Kentleşme ve Çevre Sorunları Bilim Dalı,Ankara 
Erden Ayhün, S., ve Çavuşgil Köse, B. (2018). Misyon ve vizyon ifadelerinin değerlendirilmesi: Türk yiyecek-içecek işletmelerinde bir araştırma. BMIJ, 6(2), 524-549.

Eren, E. (2002). Stratejik yönetim ve işletme politikası. İstanbul: Beta Yayınları.

Fortune. (2019, 02 08). Fortune. 02. 08. 2019 tarihinde fortuneturkey.com: http://www.fortuneturkey.com/20-yildir-kar-aciklayan-sirketler adresinden alınd 1

George, S. (1997). Focus through shared vision . National Productivity Review, 16(3), 65-74.

İnce, A. R. (2015). Türkiye'nin ikinci 500 büyük şiirketinin misyon ve vizyon ifadelerine göre girişimcilik özellikleri. Nĭ̆ge Üniversitesi İktisadi ve İdari Bilimler Fakütesi Dergisi, 8(2), 143-155.

İslamoğlu, A. H. (2011). Sosyal Bilimlerde Araştırma Yöntemleri. İstanbul: Beta Yayın.

Karaman, A. (2005). Vizyon yönetimi, nasıl ve niçin? İstanbul: IQ Yayıncllı. Kılıç, M. (2010). Stratejik Yönetim sürecinde değerler, vizyon ve misyon kavramları arasındaki ilişki. Sosyo Ekonomi Dergisi, 13(2), 81-98.

Kılıç, S. (2015). Kappa testi. Journal of Mood Disorders, 5(3), 142-144.

Kirkpatrick, S. (2008). How to Build a Better Vision Statement. Academic Leadership: The Online Journal.

Kurtuluş, K. (2010). Araştırma yöntemleri. Ankara: Türkmen Kitabevi.

Lamba, M. (2014). Büyükşehir belediyelerinde geleceğe bakış: Stratejik planlar üzerinden bir inceleme. Uluslararası Alanya İşletme Fakültesi Dergisi, 6(2), 83-96.

Latif, H., ve Muslu, Ş. (2015). Türk İşletmelerinin misyon ve vizyon kavramlarında anlam karmaşası. İstanbul Üniversitesi İşletme İktisadı Enstitüsü Yönetim Dergisi, 26(78), 12-32.

Melek, C. (2012). Metin madenciliği teknikleri ile şirketlerin vizyon ifadelerinin analizi.Yüksek Lisans Tezi, Dokuz Eylül Üniversitesi, Sosyal Bilimler Enstitüsü, Ekonometri Anabilim Dalı, Ekonometri Programı, İzmir.

Muslu, Ş. (2014). Örgütlerde misyon ve vizyon kavramlarının önemi. HAK-IŞ Uluslararası Emek ve Toplum Dergisi, 3(5), 150-171. 
Ocak, M., Güler, M., ve Basım, N. H. (2016). Türk savunma sanayi firmaları vizyon ve misyon ifadelerinin içerik analizi. Yönetim ve Ekonomi Dergisi, 23(2), 503-518.

Özer, M. A. (2010). İşletmelerin geleceği için yol haritası: Vizyon yönetimi. Çimento İşveren Dergisi, 24(6), 4-21.

Papatya, G. (1998). Vizyon: Hayal ve gerçek arasındaki gerilim - eleştirel bir yaklaşım denemesi-. Süleyman Demirel Üniversitesi İktisadi ve İdari Bilimler Fakültesi, 3(Güz), 123-134.

Sabuncuoğlu, A., ve Gök, O. (2008). Büyük işletmelerin web sitelerinde yer alan misyon ve vizyon ifadelerinin pazar odaklılık açısından incelenmesi. Afyon Kocatepe Üniversitesi, İ.I.B.F. Dergisi, 10(1), 123141.

Soygür, İ. C. (2018). Kamu ile yerli ve yabancı özel sektör bankalarının vizyon ve misyon farkları üzerine. Süleyman Demirel Üniversitesi İktisadi ve İdari Bilimler Fakültesi, 23(3), 987-1004.

Tanković, A. Č. (2013). Defining strategy using vision and mission statements of croatian organizations in times of crisis. the 6th International Conference "The Changing Economic Landscape: Issues, Implications and Policy Options"içinde (s. 331-342). May 30- Jul 1 2013,Juraj Dobrila University of Pula, Faculty of Economics and Tourism.

Ülgen, H., ve Mirze, S. K. (2013). İşletmelerde stratejik yönetim. İstanbul: Beta Yayınevi.

Yalçın, A. (2002). Değişim yönetimi. İstanbul: Nobel Yayınları.

\section{Kaynakça Bilgisi / Citation Information}

Acar, S. (2019). Şirket Karlılığı ile şirketin vizyon ifadesi arasındaki ilişkiye stratejik yönden bir bakış: BİST şirketleri üzerine bir inceleme. OPUS-Uluslararası Toplum Araştırmaları Dergisi, 12(18. UİK Özel Say1s1), 290-319. DOI: 10.26466/opus.583801. 